\title{
Osteoarthritis Progression: Mitigation and Rehabilitation Strategies
}

\begin{abstract}
Devin Drummer ${ }^{1,2}$, Jeremy McAdam ${ }^{1,2}$, Regina Seay ${ }^{1,2}$, Arny Ferrando ${ }^{3}$, S. Louis Bridges Jr. ${ }^{4,5}$, Jasvinder A. Singh ${ }^{6,7,8}$ and Marcas Bamman ${ }^{1,2,9 *}$

${ }^{1}$ UAB Center for Exercise Medicine, University of Alabama at Birmingham, Birmingham, AL, United States, ${ }^{2}$ Department of Cell, Developmental, and Integrative Biology, University of Alabama at Birmingham, Birmingham, AL, United States, ${ }^{3}$ Department of Geriatrics and Center for Translational Research in Aging and Longevity, University of Arkansas for Medical Sciences, Little Rock, AR, United States, ${ }^{4}$ Department of Medicine, Hospital for Special Surgery, New York, NY, United States, ${ }^{5}$ Division of Rheumatology, Weill Cornell Medical Center, New York, NY, United States, ${ }^{6}$ Division of Clinical Immunology and Rheumatology, University of Alabama at Birmingham, Birmingham, AL, United States, ${ }^{7}$ Department of Epidemiology, University of Alabama at Birmingham, Birmingham, AL, United States, ${ }^{8}$ Veterans Affairs Medical Center, Birmingham, AL, United States, ${ }^{9}$ Florida Institute for Human and Machine Cognition, Pensacola, FL, United States
\end{abstract}

Osteoarthritis is the most common form of arthritis and is a substantial burden for patients with the disease. Currently, there is no cure for osteoarthritis, but many emerging therapies have been developed to aid in the mitigation of disease progression. When osteoarthritis reaches the end-stage of disease many patients undergo total joint arthroplasty to improve quality of life, yet some experience persistent pain and mobility limitations for extended periods following surgery. This review highlights recent therapeutic advancements in osteoarthritis treatment consisting of pharmacologics, nutraceuticals, biologics, and exercise while emphasizing the current state of post-arthroplasty rehabilitation.

Keywords: osteoarthritis, rehabilitation, exercise, therapeutics, total joint arthroplasty

\section{INTRODUCTION}

Osteoarthritis (OA) is a disease of high research priority as tens of millions of people in the US experience its deleterious impact on mobility and quality of life. The pathogenic process in OA is distinct from other musculoskeletal aging diseases such as osteoporosis (1), and consists of the breakdown of articular cartilage in a diseased joint and compromises periarticular structures (2). While more common in the elderly and in women (3), OA does occur in younger adults and is not sex specific (4). Overall, incidence of OA has been increasing and is projected to grow to over 100 million diagnosed cases worldwide by 2050 (5). Additionally, OA causes significant economic burden, as illustrated using data from the 2015 Medical Expenditure Panel Survey which highlighted an annual excess national healthcare cost in the United States of $\$ 45$ billion for patients with OA (6). Due to these projections, preventative interventions and mitigation strategies for the disease have been developed. Prior to 2017, many reviews summarized the state of the field concerning OA and potential interventions such as exercise (7-9). One such review was written by Pedersen and Saltin, two pioneers in the muscle biology field, highlighted exercise as medicine for OA and suggested possible mechanisms for how exercise acts as an analgesic and attenuates inflammatory mediators of the disease (10). However, a recent commentary from our group highlighted the unsettling reality of high incidence of inactivity among individuals with $\mathrm{OA}$ 
even in light of the preponderance of evidence supporting the benefits of exercise on OA pathology and symptomology (9). This prior review discussed what was known at the time with respect to exercise medicine in $\mathrm{OA}$ and highlighted potential avenues for significant scientific breakthroughs in the OA field. The current mini-review aims to highlight the strides made in recent years, as well as summarize the current state of knowledge on the molecular underpinnings of OA and how the periarticular physiology seems to both contribute and be impacted, particularly in the context of recovery following total joint arthroplasty (TJA) - a definitive surgical treatment for endstage OA. The literature search consisted of probing PubMed with search terms coupled with osteoarthritis such as: etiology, rehabilitation, exercise, treatments, nutraceuticals, and total joint arthroplasty with an emphasis on human literature since 2015. Any omitted topics were due to space constraints, and do not reflect a lack of importance of the research.

\section{Etiology of OA}

$\mathrm{OA}$ is the most common joint disease, characterized by the failure of the joint as an organ (11). Knee OA is the largest culprit of physical disability in the world $(5,12)$. Many factors contribute to the pathogenesis of $\mathrm{OA}$, which is defined as the maladaptation of a joint and its periarticular structures (2). Lifestyle factors such as previous connective tissue injuries, obesity (13), and advancing age (2), appear to increase the likelihood of symptomatic OA. Until recently, OA was generally considered a non-inflammatory disorder; however, there is growing evidence that inflammation contributes significantly to OA (14), and that inflammation is a key regulator of osteoarthritis pathogenesis (15). Furthermore, it appears that tissues in direct contact with the arthritic joint may be susceptible to overt pro-inflammatory signaling (2, 16). Specifically, signal transduction pathways such as tumor necrosis-factor like weak inducer of apoptosis (TWEAK) and receptor fibroblast inducible factor 14 (Fn14), tumor necrosisfactor alpha (TNF- $\alpha$ ) and receptor (TNF- $\alpha \mathrm{R})$, as well as Interleukin-6 (IL-6) and receptor (IL-6R) are implicated in chondrocyte senescence and dysregulation of periarticular tissues such as skeletal muscle through activation of the transcription factors nuclear factor kappa-light-chain-enhancer of activated B cells $(\mathrm{NF} \kappa \mathrm{B})$ and signal transducer and activator of transcription 3 (STAT3) $(16,17)$. Such data highlight the possibility for OA biomarkers that could be used to guide treatment that optimizes the mitigation of disease progression.

Further interrogation of potential biomarkers of OA have largely been viewed from the context of chondrocytes (1822), the cells responsible for cartilage formation. Their distinct phenotype is influenced by the state of the joint as a whole and they secrete numerous factors to regulate joint health (18). Enzymes such as A Disintegrin and Metalloproteinase with Thrombospondin motifs (ADAMTS) possess anabolic and catabolic roles in cartilage with high expression of ADAMTS7 and ADAMTS-12 being implicated in OA pathogenesis (23). Furthermore, proteins such as chitinase-3-like-protein1 (CHI3L1), a synovial fluid and serum marker of OA, is linked to matrix metalloproteinase (MMP) activity as well as inflammatory interleukin signaling (18). Other markers of
OA progression such as cartilage acidic protein-1 (CRTAC1), high temperature requirement A serine peptidase-1 (HTRA1), gremlin-1 and others have been identified using proteomic methods (18). In some instances, it is necessary to probe the chondrocytes or chondrocyte explants with common in vivo drivers of $\mathrm{OA}$ such as IL- $1 \beta$ to elicit a divergence in OA chondrocyte secretion of inflammatory mediators (e.g., cytokines and chemokines) relative to healthy cells (18). Furthermore, increased disease severity appears to drive greater inflammatory signaling such as expression of the transcription factor NFKB and proteolytic enzyme MMP-13, both associated with cartilage degradation (19). Using logistical regression Liu et al. report that exercise may mitigate some of these deleterious signaling events (19). SIRT1 decline has been linked to MMP activity and OA, but when elevated due to exercise, SIRT1 appears protective for chondrocytes and hyaline cartilage $(20,22,24)$. Therefore, inflammation seems to be a key mechanism of OA pathogenesis, but exercise may be a potential means to overcome this deleterious signaling.

While chondrocytes have been heavily studied as a source of potential OA biomarkers, the other periarticular tissues may provide additional insight necessary to distinguish an OA signature vs. other conditions such as aging or osteoporosis (21). In a recent review, Henrotin et al. suggested that well-designed 'omics studies, or multiplexing of known biomarkers such as Coll2-1 and PIIANP for collagen breakdown and synthesis, respectively, coupled with histological images and functional phenotyping optimize chances for a definitive OA prognostic panel (21). Due to the interconnectivity of periarticular tissues, we agree with Henrotin and others, and further suggest that integrative analyses of signatures from cartilage and surrounding tissues are needed to understand the complex interrelationships at play. For example, it appears that signaling molecules from skeletal muscle can drastically influence the health of bone and its surrounding structures $(25,26)$. Furthermore, it appears that increased skeletal muscle strength surrounding the diseased joint can mitigate OA symptoms $(27,28)$. Moving forward, to better understand the etiology of OA and how best to overcome it, more well-controlled integrative molecular mapping and signaling studies are a high research priority.

\section{OA Treatments}

Many treatments exist for OA, and major guidelines have recently been published providing recommendations for their usage (29-31). Most currently available treatments primarily target symptom management as opposed to disease pathobiology. There are currently no therapeutic agents that reverse or halt OA progression, resulting in continued disease progression in millions of patients with OA (30-32). A summary of the treatments covered in this review can be found in Table $\mathbf{1}$.

\section{Pharmacologics}

Drugs such as non-steroidal anti-inflammatory drugs (NSAIDs) and intra-articular glucocorticoids are widely used to manage inflammation and pain, but they are best for short-term use (33) as long-term use can lead to significant toxicities (33). Further, the effectiveness of glucocorticoids diminishes over time, 
TABLE 1 | Summary of discussed osteoarthritis treatments and their proposed effects.

\begin{tabular}{|c|c|}
\hline Treatment & Effect \\
\hline \multicolumn{2}{|l|}{ Pharmacologics } \\
\hline $\begin{array}{l}\text { Non-steroidal anti-inflammatory } \\
\text { drugs }\end{array}$ & Anti-inflammatory and analgesic (33) \\
\hline Intra-articular glucocorticoids & $\begin{array}{l}\text { Anti-inflammatory and analgesic } \\
(33,34)\end{array}$ \\
\hline Opioids & Analgesic (35) \\
\hline \multicolumn{2}{|l|}{ Nutraceuticals } \\
\hline Blueberries & Analgesic $(36,37)$ \\
\hline Montmorency Cherry Juice & $\begin{array}{l}\text { Anti-inflammatory and analgesic } \\
(37-39)\end{array}$ \\
\hline Glucosamine and/or Chondroitin & $\begin{array}{l}\text { Anti-inflammatory and analgesic } \\
(40-44)\end{array}$ \\
\hline Curcumin/turmeric & $\begin{array}{l}\text { Anti-inflammatory and analgesic } \\
(45,46)\end{array}$ \\
\hline \multicolumn{2}{|l|}{ Biologics } \\
\hline Platelet rich plasma & Anti-inflammatory (47-52) \\
\hline Stem cell therapies & $\begin{array}{l}\text { Potential tissue regrowth and } \\
\text { analgesic (53-55) }\end{array}$ \\
\hline Nerve growth factor antibodies & Anti-inflammatory and analgesic (56) \\
\hline Fibroblast growth factor 18 & Chondroprotective (57) \\
\hline $\begin{array}{l}\text { Interleukin } 1 \text { alpha/beta } \\
\text { antagonists }\end{array}$ & Anti-inflammatory (58) \\
\hline \multicolumn{2}{|l|}{ Exercise } \\
\hline Aquatic exercise & $\begin{array}{l}\text { Analgesic and improved physical } \\
\text { function (59-62) }\end{array}$ \\
\hline Aerobic exercise (weight bearing) & $\begin{array}{l}\text { Analgesic and improved physical } \\
\text { function }(63,64)\end{array}$ \\
\hline Resistance exercise & $\begin{array}{l}\text { Analgesic and improved physical } \\
\text { function (64-66) }\end{array}$ \\
\hline $\begin{array}{l}\text { Blood flow restriction (BFR) } \\
\text { exercise }\end{array}$ & $\begin{array}{l}\text { Analgesic and improved physical } \\
\text { function }(67,68)\end{array}$ \\
\hline
\end{tabular}

which limits their utility for long-term use in OA (33). Longterm repeated intra-articular glucocorticoid injections may be detrimental to cartilage volume in some OA patient populations due to degradative effects on musculoskeletal tissues (34).

\section{Nutraceuticals}

Due to the lack of substantive benefit and risks of chronic opioid use in OA (35), nutraceuticals have come into the fray for improving quality of life. Specifically, blueberries (36), Montmorency Cherry Juice (38), glucosamine and/or chondroitin (40-42), and curcumin/turmeric (45, 46) have been interrogated. Blueberries and Montmorency Cherry Juice possess large anthocyanin contents which have been shown to attenuate the cyclooxygenase II (COX2) pathway potentially leading to a decrease in pain $(37,39)$. Both treatments improved Western Ontario McMaster Osteoarthritis Index (WOMAC), and Montmorency Cherry Juice improved high sensitivity Creactive protein $(36,39)$. However, blueberry use did not improve plasma markers of inflammation (36). Glucosamine also acts as an anti-inflammatory via the COX2 pathway; the data on its effectiveness in OA treatment are mixed $(43,44)$, but some encouraging data exist for pain relief (41). Recent systematic reviews of curcumin/turmeric extracts or chondroitin suggest modest pain benefits with little to no untoward side effects $(42,45,46)$. Overall, it appears nutraceuticals may help improve quality of life for those suffering with $\mathrm{OA}$ without the negative side effects of traditional pharmacological agents. However, largescale, double-blind, randomized controlled trials to evaluate long term effectiveness of nutraceuticals are warranted, particularly in light of the placebo effect often associated with such compounds.

\section{Biologics}

Recent technological advancements have prompted new treatments for OA such as platelet rich plasma (PRP) (47-50), intra-articular delivery systems (33), stem cell therapies (53-55), and antibodies to nerve growth factor (NGF) (56). There is still much to be learned about these potential therapies, but some initial findings have been purported. PRP is derived from plasma, and through centrifugation, a concentration of platelets can then be reinjected into the diseased body location $(47,51)$. PRP is suggested to elicit beneficial changes in the OA joint by quenching the pro-inflammatory signaling cascade through the application of activated PRP containing high concentrations of growth factors, fibrin, and other molecules (49, 51, 52). Intra-articular delivery systems often function by modifying pro-inflammatory molecules through pharmacologic agents such as NSAIDs or steroids bound to particles that can be injected into the diseased joint (33). While these treatments may have promise, the contraindications of frequent injections or possible infection must be considered (33), and as with nutraceuticals, large-scale, double-blind, randomized controlled trials are limited $(69,70)$.

With stem cell therapies there is vast diversity in the cell source and application method within the joint (55). This heterogeneity accompanied with different study designs and an inability to fully quantify treatment effectiveness makes it difficult to determine the breadth of effectiveness of cell-based treatments (55). However, some recent well-controlled clinical trials (54) illustrate promising improvements in functional/pain scales such as WOMAC following the implantation of autologous bone marrow-derived mesenchymal stromal cells in patients with knee OA. The potential for stem cell therapies is immense as degenerated tissue may be regrown; however, sufficient data are lacking as to the long-term benefits and risks.

Another innovative treatment for patients with $\mathrm{OA}$ is the use of antibodies to block the pain signaling of NGF (56). NGF stimulates increased inflammation, and secretion of calcitonin gene-related peptide and substance $\mathrm{P}$ which relay pain signals through the nociceptor neuron (56). Antibody based inhibitors of NGF and/or its receptors have proven effective in mitigating pain and improving function in patients with $\mathrm{OA}$, but at higher doses may be detrimental to disease progression (56). Several developmental programs for NGF therapies are on hold, but some are continuing. Therefore, it is vital to determine the mechanisms by which anti-NGF antibodies may negatively influence OA joint health at higher doses if it is to be widely used for pain management and quality of life improvement in OA. New data are emerging for additional biologic treatments 


\section{Exercise}

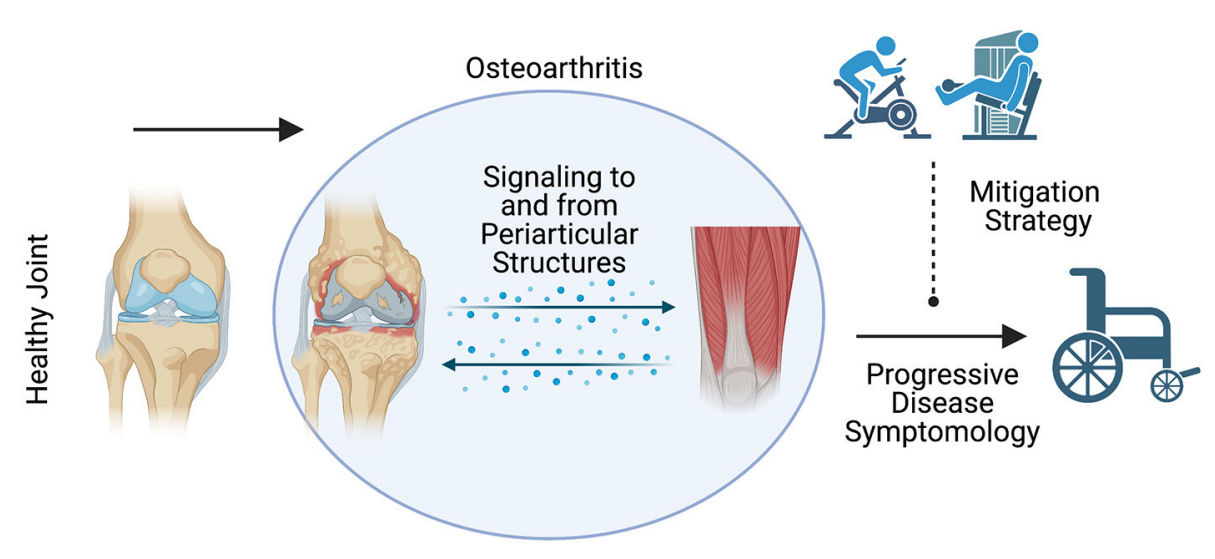

FIGURE 1 | Schematic representation of the expected influence of exercise on osteoarthritis disease symptomology. Exercise may be a viable means to mitigate the deleterious symptoms associated with osteoarthritis disease progression.

including FGF18 which may be chondroprotective (57) and IL- $1 \alpha / \beta$ antagonists which may act to quench inflammatory signaling in OA (58).

\section{Exercise}

As previously mentioned, a viable treatment option to mitigate OA progression is exercise $(9,10)$. This should come as no surprise as exercise has been shown to elicit numerous signaling changes to the extent that it has been described as the "real polypill" (71). Numerous reviews, meta-analyses and primary studies have been conducted since 2016 interrogating the influence of various exercise modalities and physical activity on OA (59-61, 63-67, 72-90), and the American College of Rheumatology/Arthritis Foundation strongly recommend exercise for OA treatment (29). While strongly recommended, the guidelines for exercise prescription lack specificity due to an underabundance of data (29). Furthermore, vast differences in exercise modality and prescription make comparisons difficult across studies.

For instance, water based exercise training is a common modality as it minimizes the weight bearing load upon the joint and can minimize pain (62); however, the data concerning its effectiveness appear mixed and are often muddled by the inclusion of multiple exercise modalities in and out of the water (59-61). Further, the efficacy of other exercise modalities depends on the outcome of interest (64). Land-based aerobic exercise such as self-selected running does not appear to promote radiographically assessed joint degradation (63) while improving pain and physical function (64). Resistance training appears to elicit similar outcomes (64), and even when performed explosively appears to be a safe means of training for patients with OA (65). While traditional resistance training appears safe, resistance training protocols such as blood flow restriction (BFR) may also be viable while minimizing pain during exercise. Blood flow restriction is a resistance training method that utilizes low loads while applying an occlusion cuff proximal to the muscles being contracted (68). In patients with OA, BFR elicited similar gains in strength, quadriceps cross-sectional area, and timed stand repetitions compared to high intensity resistance training (67). Overall, the data seem to support beneficial outcomes associated with exercise (Figure 1), but the specific benefits such as pain or strength improvement seem to be dictated by exercise programming. Recently, a systematic review by Turner et al. described moderate to large effect sizes for pain and functional outcomes associated with approximately 24 sessions across 8-12 weeks of resistance training (66). However, the need for comprehensive studies interrogating optimal volume, intensity, frequency, exercise selection and mode of delivery are needed to continue the strides made toward best practices for exercise training to treat OA. Adherence to exercise as a longterm OA treatment modality is another major challenge (91). Future studies of behavioral interventions to increase long-term adherence to exercise are also needed.

\section{End-Stage OA and Rehabilitation Following Total Joint Arthroplasty}

End-stage $\mathrm{OA}$ is often symptomatically described as a severe decline in the functionality of the affected joint (92), commonly accompanied by severe pain (93), and in some instances presents as bone on bone contact radiographically (94). In end-stage knee OA, elevated pro-inflammatory markers such as IL-6 in synovial fluid, have been associated with pain, joint swelling, and synovitis (95). Furthermore, ADAMTS enzymes have been implicated in cartilage degradation (23), with ADAMTS-4 and-5 specifically linked to knee OA (96). Interestingly, end-stage OA of the hip and knee may differ mechanistically as recent evidence purports decreased ADAMTS-4 and-5 in patients with hip OA (97), contrary to what has been shown in knee OA (96). Furthermore, work from our group has also described heterogeneity among patients with the same diseased joint, end-stage hip OA. This work reported that a subset of patients with end-stage hip OA possess profound pro-inflammatory gene expression within the skeletal muscle surrounding the diseased joint, described as 
muscle inflammation susceptibility (16). Taken together there appears to be a robust inflammatory cascade in the tissues comprising a joint in the end-stage of OA. This results in pain, functional deficits, and decreased quality of life that often drive patients to elect TJA as a surgical treatment.

TJA is a common procedure that provides many patients with relief from the moderate to severe symptoms of endstage OA (98). Unfortunately, not all patients have the same beneficial experience, as many suffer a persistent pain and mobility impairment following the procedure $(99,100)$. Some data suggest pre-surgical frailty leads to higher incidence of poor post-surgical outcomes (101). This is further supported by data illustrating decreased muscle integrity at the wholemuscle and histological levels (102). Work from our research program furthers the notion that overt pro-inflammatory signaling (muscle inflammation susceptibility) in skeletal muscle surrounding the diseased joint is associated with diminished rates of muscle protein synthesis (16). To counteract the poor physiological characteristics of peri-articular muscles leading up to joint replacement, and to diminish the effects of trauma associated with joint repair, many studies have aimed to optimize the rehabilitation process. Unfortunately, there has yet to be a standardized prehabilitation (30) or post-operative rehabilitation protocol within the field $(103,104)$. This may be in part due to the heterogeneity in recovery outcomes $(100,105)$, but the consistent lack of appropriate rehabilitation dosage for recovery cannot be ignored (104). Therefore, it is crucial to establish rehabilitation recommendations that effectively address functional limitations following TJA.

A wide range of rehabilitation approaches, perhaps best characterized as "usual care," has yielded varying levels of efficacy post-TJA. However, many groups including our own hypothesize that progressive and intensive resistance training may be a key ingredient to optimize patient outcomes after joint replacement. When compared to usual care, progressive resistance training (PRT) improves functional measures such as leg press strength without increasing pain (106). Furthermore, a recent meta-analysis indicated progressive resistance training significantly enhances knee extension strength on the surgical limb (107). Results of studies using other functional outcomes such as 6 min walk test ( $6 \mathrm{MWT}$ ) appear to be inconsistent. Some authors purport no change following PRT $(106,107)$, while others illustrate improvements, but suffer from lack of comparison to a usual care group $(108,109)$. In general, it appears that quadriceps strength is correlated with the 6 MWT (110), but more data are needed. Encouragingly, supervised PRT has been shown to overcome inflammatory and disuse associated conditions such as aging or bedrest (111-114); therefore, it is logical to posit that provided with appropriate stimulus, treatment of OA with PRT would be effective. However, there are insufficient data and great variability in rehabilitation

\section{REFERENCES}

1. Chandra A, Rajawat J. Skeletal aging and osteoporosis: mechanisms and therapeutics. Int J Mol Sci. (2021) 22:3553. doi: 10.3390/ijms22073553 programming with regard to post-TJA and exercise training for rehabilitation $(107,115,116)$. The field remains in a state of need for well-controlled, randomized clinical trials that assess the functional impact of PRT vs. usual care and shed light on the mechanistic underpinnings differentiating these widely divergent rehabilitation approaches. Work addressing these issues would provide a needed basis for optimized exercise programming following TJA, potentially lead to pharmacological adjuvants, and improve the likelihood of successful recovery following surgery.

\section{CONCLUSIONS}

OA remains a complex disease state that is not fully understood. However, remarkable strides have been made recently that aim to promote improved functionality and quality of life for those living with the disease. These advancements aim to potentially prevent or at least prolong the time before patients undergo more invasive procedures such as TJA. While TJA appears effective for many, little is known about why some patients continue to suffer from severe symptoms following the procedure, with even less known about how to optimally alleviate these problems. Exercise in particular appears to beneficial as a treatment for pain management and functional improvements with $\mathrm{OA}$, and progressive resistance training may be necessary to optimally recover following TJA. However, many uncertainties persist within the field which limit the impact of exercise as an effective treatment or therapeutic option. To overcome this, comprehensive large-scale rehabilitation clinical trials are needed to better inform practitioners moving forward with rehabilitative care.

\section{AUTHOR CONTRIBUTIONS}

DD co-conceptualized the manuscript, performed literature search, and wrote the manuscript. MB co-conceptualized the manuscript, edited the manuscript, and provided additional literature for inclusion. JM, RS, AF, SB, and JS edited the manuscript and provided additional literature for inclusion. All authors contributed to manuscript revision, read, and approved the submitted version.

\section{FUNDING}

All funding for this work was provided by Eunice Kennedy Shriver National Institute of Child Health and Human Development (NICHD): T32HD071866, R01HD084124, P2CHD086851.

\section{ACKNOWLEDGMENTS}

Figure 1 was created with BioRender.com.

2. Mobasheri A, Batt M. An update on the pathophysiology of osteoarthritis Ann Phys Rehabil Med. (2016) 59:333-9. doi: 10.1016/j.rehab.2016.07.004

3. Anderson AS, Loeser RF. Why is osteoarthritis an age-related disease? Best Pract Res Clin Rheumatol. (2010) 24:15. doi: 10.1016/j.berh.2009.08.006 
4. Ackerman IN, Kemp JL, Crossley KM, Culvenor AG, Hinman RS. Hip and knee osteoarthritis affects younger people, too. J Orthop Sports Phys Ther. (2017) 47:67-79. doi: 10.2519/jospt.2017.7286

5. Mobasheri A, Saarakkala S, Finnilä M, Karsdal MA, Bay-Jensen AC, van Spil WE. Recent advances in understanding the phenotypes of osteoarthritis. F1000Research. (2019) 8:F1000. doi: 10.12688/f1000research.2 0575.1

6. Zhao X, Shah D, Gandhi K, Wei W, Dwibedi N, Webster L, et al. Clinical, humanistic, and economic burden of osteoarthritis among noninstitutionalized adults in the United States. Osteoarthritis Cartilage. (2019) 27:1618-26. doi: 10.1016/j.joca.2019.07.002

7. Fransen M, McConnell S, Harmer AR, Esch MV der, Simic M, Bennell KL. Exercise for osteoarthritis of the knee: a Cochrane systematic review. $\mathrm{Br} \mathrm{J}$ Sports Med. (2015) 49:1554-7. doi: 10.1136/bjsports-2015-095424

8. Li Y, Su Y, Chen S, Zhang Y, Zhang Z, Liu C, et al. The effects of resistance exercise in patients with knee osteoarthritis: a systematic review and metaanalysis. Clin Rehabil. (2016) 30:947-59. doi: 10.1177/0269215515610039

9. Bamman MM, Wick TM, Carmona-Moran CA, Bridges SL. Exercise medicine for osteoarthritis: research strategies to maximize effectiveness. Arthritis Care Res. (2016) 68:288-91. doi: 10.1002/acr. 22680

10. Pedersen BK, Saltin B. Exercise as medicine - evidence for prescribing exercise as therapy in 26 different chronic diseases. Scand J Med Sci Sports. (2015) 25:1-72. doi: $10.1111 /$ sms.12581

11. Loeser RF, Goldring SR, Scanzello CR, Goldring MB. Osteoarthritis: a disease of the joint as an organ. Arthritis Rheum. (2012) 64:1697-707. doi: 10.1002/art.34453

12. Hart HF, Stefanik JJ, Wyndow N, Machotka Z, Crossley KM. The prevalence of radiographic and MRI-defined patellofemoral osteoarthritis and structural pathology: a systematic review and meta-analysis. Br J Sports Med. (2017) 51:1195-208. doi: 10.1136/bjsports-2017-097515

13. Antony B, Jones G, Jin X, Ding C. Do early life factors affect the development of knee osteoarthritis in later life: a narrative review. Arthritis Res Ther. (2016) 18:202. doi: 10.1186/s13075-016-1104-0

14. Wang Q, Rozelle AL, Lepus CM, Scanzello CR, Song JJ, Larsen DM, et al. Identification of a central role for complement in osteoarthritis. Nat Med. (2011) 17:1674-9. doi: 10.1038/nm.2543

15. Robinson WH, Lepus CM, Wang Q, Raghu H, Mao R, Lindstrom $\mathrm{TM}$, et al. Low-grade inflammation as a key mediator of the pathogenesis of osteoarthritis. Nat Rev Rheumatol. (2016) 12:580-92. doi: 10.1038/nrrheum.2016.136

16. Bamman MM, Ferrando AA, Evans RP, Stec MJ, Kelly NA, Gruenwald JM, et al. Muscle inflammation susceptibility: a prognostic index of recovery potential after hip arthroplasty? Am J Physiol - Endocrinol Metab. (2015) 308:E670-9. doi: 10.1152/ajpendo.005 76.2014

17. Greene MA, Loeser RF. Aging-related inflammation in osteoarthritis. Osteoarthr Cartil OARS Osteoarthr Res Soc. (2015) 23:1966-71. doi: 10.1016/j.joca.2015.01.008

18. Sanchez C, Bay-Jensen A-C, Pap T, Dvir-Ginzberg M, Quasnichka H, BarrettJolley R, et al. Chondrocyte secretome: a source of novel insights and exploratory biomarkers of osteoarthritis. Osteoarthritis Cartilage. (2017) 25:1199-209. doi: 10.1016/j.joca.2017.02.797

19. Liu Y-X, Wang G-D, Wang X, Zhang Y-L, Zhang T-L. Effects of TLR2/NF- $\mathrm{KB}$ signaling pathway on the occurrence of degenerative knee osteoarthritis: an in vivo and in vitro study. Oncotarget. (2017) 8:38602-17. doi: 10.18632/oncotarget.16199

20. Elayyan J, Lee E-J, Gabay O, Smith CA, Qiq O, Reich E, et al. LEF1mediated MMP13 gene expression is repressed by SIRT1 in human chondrocytes. FASEB J Off Publ Fed Am Soc Exp Biol. (2017) 31:3116-25. doi: 10.1096/fj.201601253R

21. Henrotin Y, Sanchez C, Bay-Jensen AC, Mobasheri A. Osteoarthritis biomarkers derived from cartilage extracellular matrix: current status and future perspectives. Ann Phys Rehabil Med. (2016) 59:145-8. doi: 10.1016/j.rehab.2016.03.004

22. Dvir-Ginzberg M, Mobasheri A, Kumar A. The role of sirtuins in cartilage homeostasis and osteoarthritis. Curr Rheumatol Rep. (2016) 18:43. doi: 10.1007/s11926-016-0606-8
23. Yang C-Y, Chanalaris A, Troeberg L. ADAMTS and ADAM metalloproteinases in osteoarthritis - looking beyond the "usual suspects." Osteoarthritis Cartilage. (2017) 25:1000-9. doi: 10.1016/j.joca.2017. 02.791

24. Vargas-Ortiz K, Pérez-Vázquez V, Macías-Cervantes MH. Exercise and sirtuins: a way to mitochondrial health in skeletal muscle. Int J Mol Sci. (2019) 20:2717. doi: 10.3390/ijms20112717

25. Brotto $\mathrm{M}$, Bonewald $\mathrm{L}$. Bone and muscle: interactions beyond mechanical. Bone. (2015) 80:109-14. doi: 10.1016/j.bone.2015.02.010

26. Cardozo CP, Graham ZA. Muscle-bone interactions: movement in the field of mechano-humoral coupling of muscle and bone. Ann N Y Acad Sci. (2017) 1402:10-7. doi: 10.1111/nyas.13411

27. Bacon KL, Segal NA, Øiestad BE, Lewis CE, Nevitt MC, Brown C, et al. Concurrent change in quadriceps strength and physical function over five years in the multicenter osteoarthritis study. Arthritis Care Res. (2019) 71:1044-51. doi: 10.1002/acr.23754

28. Hall M, Hinman RS, Wrigley TV, Kasza J, Lim B-W, Bennell KL. Knee extensor strength gains mediate symptom improvement in knee osteoarthritis: secondary analysis of a randomised controlled trial. Osteoarthritis Cartilage. (2018) 26:495-500. doi: 10.1016/j.joca.2018. 01.018

29. Kolasinski SL, Neogi T, Hochberg MC, Oatis C, Guyatt G, Block J, et al. 2019 American College of Rheumatology/Arthritis Foundation Guideline for the Management of Osteoarthritis of the Hand, Hip, and Knee. Arthritis Rheumatol. (2020) 72:220-33. doi: 10.1002/art. 41142

30. Jette DU, Hunter SJ, Burkett L, Langham B, Logerstedt DS, Piuzzi NS, et al. Physical therapist management of total knee arthroplasty. Phys Ther. (2020) 100:1603-31. doi: 10.1093/ptj/pzaa099

31. Bannuru RR, Osani MC, Vaysbrot EE, Arden NK, Bennell K, BiermaZeinstra SMA, et al. OARSI guidelines for the non-surgical management of knee, hip, and polyarticular osteoarthritis. Osteoarthritis Cartilage. (2019) 27:1578-89. doi: 10.1016/j.joca.2019.06.011

32. Charlesworth J, Fitzpatrick J, Perera NKP, Orchard J. Osteoarthritisa systematic review of long-term safety implications for osteoarthritis of the knee. BMC Musculoskelet Disord. (2019) 20:151. doi: 10.1186/s12891-019-2525-0

33. Kou L, Xiao S, Sun R, Bao S, Yao Q, Chen R. Biomaterial-engineered intraarticular drug delivery systems for osteoarthritis therapy. Drug Deliv. (2019) 26:870-85. doi: 10.1080/10717544.2019.1660434

34. McAlindon TE, LaValley MP, Harvey WF, Price LL, Driban JB, Zhang M, et al. Effect of intra-articular triamcinolone vs saline on knee cartilage volume and pain in patients with knee osteoarthritis: a randomized clinical trial. JAMA. (2017) 317:1967-75. doi: 10.1001/jama.2017. 5283

35. Ivers N, Dhalla IA, Allan GM. Opioids for osteoarthritis pain: benefits and risks. Can Fam Physician. (2012) 58:e708.

36. Du C, Smith A, Avalos M, South S, Crabtree K, Wang W, et al. Blueberries improve pain, gait performance, and inflammation in individuals with symptomatic knee osteoarthritis. Nutrients. (2019) 11:290. doi: 10.3390/nu11020290

37. Seeram N. Cyclooxygenase inhibitory and antioxidant cyanidin glycosides in cherries and berries. Phytomedicine. (2001) 8:362-9. doi: 10.1078/0944-7113-00053

38. Schumacher HR, Pullman-Mooar S, Gupta SR, Dinnella JE, Kim R, McHugh MP. Randomized double-blind crossover study of the efficacy of a tart cherry juice blend in treatment of osteoarthritis (OA) of the knee. Osteoarthritis Cartilage. (2013) 21:1035-41. doi: 10.1016/j.joca.2013.05.009

39. Tall JM, Seeram NP, Zhao C, Nair MG, Meyer RA, Raja SN. Tart cherry anthocyanins suppress inflammation-induced pain behavior in rat. Behav Brain Res. (2004) 153:181-8. doi: 10.1016/j.bbr.2003.11.011

40. Naumov AV, Tkacheva ON. Use of a glycosamine sulfate for patients with osteoarthritis and a comorbidity with high risk of the side effects from NSAIDS. Ter Arkh. (2018) 90:81-7. doi: 10.26442/terarkh201890581-87

41. Gregori D, Giacovelli G, Minto C, Barbetta B, Gualtieri F, Azzolina D, et al. Association of pharmacological treatments with long-term pain control in patients with knee osteoarthritis: a systematic review and meta-analysis. JAMA. (2018) 320:2564-79. doi: 10.1001/jama.2018.19319 
42. Singh JA, Noorbaloochi S, MacDonald R, Maxwell LJ. Chondroitin for osteoarthritis. Cochrane Database Syst Rev. (2015) 1:CD005614. doi: 10.1002/14651858.CD005614.pub2

43. Herrero-Beaumont G, Largo R. Glucosamine and O-GlcNAcylation: a novel immunometabolic therapeutic target for $\mathrm{OA}$ and chronic, low-grade systemic inflammation? Ann Rheum Dis. (2020) 79:1261-3. doi: 10.1136/annrheumdis-2020-217454

44. Sawitzke AD, Shi H, Finco MF, Dunlop DD, Harris CL, Singer NG, et al. Clinical efficacy and safety of glucosamine, chondroitin sulphate, their combination, celecoxib or placebo taken to treat osteoarthritis of the knee: 2-year results from GAIT. Ann Rheum Dis. (2010) 69:1459-64. doi: 10.1136/ard.2009.120469

45. Paultre K, Cade W, Hernandez D, Reynolds J, Greif D, Best TM. Therapeutic effects of turmeric or curcumin extract on pain and function for individuals with knee osteoarthritis: a systematic review. BMJ Open Sport Exerc Med. (2021) 7:e000935. doi: 10.1136/bmjsem-2020-0 00935

46. Wang Z, Singh A, Jones G, Winzenberg T, Ding C, Chopra A, et al. Efficacy and safety of turmeric extracts for the treatment of knee osteoarthritis: a systematic review and meta-analysis of randomised controlled trials. Curr Rheumatol Rep. (2021) 23:11. doi: 10.1007/s11926-020-0 0975-8

47. O'Connell B, Wragg NM, Wilson SL. The use of PRP injections in the management of knee osteoarthritis. Cell Tissue Res. (2019) 376:143-52. doi: 10.1007/s00441-019-02996-x

48. Paterson KL, Nicholls M, Bennell KL, Bates D. Intra-articular injection of photo-activated platelet-rich plasma in patients with knee osteoarthritis: a double-blind, randomized controlled pilot study. BMC Musculoskelet Disord. (2016) 17:67. doi: 10.1186/s12891-016-0920-3

49. Bennell KL, Hunter DJ, Paterson KL. Platelet-rich plasma for the management of hip and knee osteoarthritis. Curr Rheumatol Rep. (2017) 19:24. doi: 10.1007/s11926-017-0652-x

50. Paterson KL, Hunter DJ, Metcalf BR, Eyles J, Duong V, Kazsa J, et al. Efficacy of intra-articular injections of platelet-rich plasma as a symptom- and disease-modifying treatment for knee osteoarthritis the RESTORE trial protocol. BMC Musculoskelet Disord. (2018) 19:272. doi: 10.1186/s12891-018-2205-5

51. Moussa M, Lajeunesse D, Hilal G, El Atat O, Haykal G, Serhal $\mathrm{R}$, et al. Platelet rich plasma (PRP) induces chondroprotection via increasing autophagy, anti-inflammatory markers, and decreasing apoptosis in human osteoarthritic cartilage. Exp Cell Res. (2017) 352:146-56. doi: 10.1016/j.yexcr.2017.02.012

52. Laudy ABM, Bakker EWP, Rekers M, Moen MH. Efficacy of plateletrich plasma injections in osteoarthritis of the knee: a systematic review and meta-analysis. Br J Sports Med. (2015) 49:657-72. doi: 10.1136/bjsports-2014-094036

53. Choi Y-R, Collins KH, Lee J-W, Kang H-J, Guilak F. Genome Engineering for osteoarthritis: from designer cells to disease-modifying drugs. Tissue Eng Regen Med. (2019) 16:335-43. doi: 10.1007/s13770-0180172-4

54. Emadedin M, Labibzadeh N, Liastani MG, Karimi A, Jaroughi $\mathrm{N}$, Bolurieh $\mathrm{T}$, et al. Intra-articular implantation of autologous bone marrow-derived mesenchymal stromal cells to treat knee osteoarthritis: a randomized, triple-blind, placebo-controlled phase $1 / 2$ clinical trial. Cytotherapy. (2018) 20:1238-46. doi: 10.1016/j.jcyt.2018. 08.005

55. Shariatzadeh M, Song J, Wilson SL. The efficacy of different sources of mesenchymal stem cells for the treatment of knee osteoarthritis. Cell Tissue Res. (2019) 378:399-410. doi: 10.1007/s00441-019-03069-9

56. Wise BL, Seidel MF, Lane NE. The evolution of nerve growth factor inhibition in clinical medicine. Nat Rev Rheumatol. (2021) 17:34-46. doi: 10.1038/s41584-020-00528-4

57. McClurg O, Tinson R, Troeberg L. Targeting cartilage degradation in osteoarthritis. Pharmaceuticals. (2021) 14:126. doi: 10.3390/ph14020126

58. Wang SX, Abramson SB, Attur M, Karsdal MA, Preston RA, Lozada CJ, et al. Safety, tolerability, and pharmacodynamics of an anti-interleukin- $1 \alpha / \beta$ dual variable domain immunoglobulin in patients with osteoarthritis of the knee: a randomized phase 1 study. Osteoarthritis Cartilage. (2017) 25:1952-61. doi: 10.1016/j.joca.2017.09.007

59. Mattos F de, Leite N, Pitta A, Bento PCB. Effects of aquatic exercise on muscle strength and functional performance of individuals with osteoarthritis: a systematic review. Rev Bras Reumatol. (2016) 56:530-42. doi: 10.1016/j.rbre.2016.09.003

60. Sahin HG, Kunduracilar Z, Sonmezer E, Ayas S. Effects of two different aquatic exercise trainings on cardiopulmonary endurance and emotional status in patients with knee osteoarthritis. J Back Musculoskelet Rehabil. (2019) 32:539-48. doi: 10.3233/BMR-171116

61. Dong $\mathrm{R}, \mathrm{Wu} \mathrm{Y}, \mathrm{Xu} \mathrm{S}$, Zhang $\mathrm{L}$, Ying J, Jin $\mathrm{H}$, et al. Is aquatic exercise more effective than land-based exercise for knee osteoarthritis? Medicine (Baltimore). (2018) 97:e13823. doi: 10.1097/MD.00000000000 13823

62. Kim I-S, Chung S-H, Park Y-J, Kang H-Y. The effectiveness of an aquarobic exercise program for patients with osteoarthritis. Appl Nurs Res. (2012) 25:181-9. doi: 10.1016/j.apnr.2010.10.001

63. Lo GH, Musa SM, Driban JB, Kriska AM, McAlindon TE, Souza RB, et al. Running does not increase symptoms or structural progression in people with knee osteoarthritis: data from the osteoarthritis initiative. Clin Rheumatol. (2018) 37:2497-504. doi: 10.1007/s10067-018-4 $121-3$

64. Goh S-L, Persson MSM, Stocks J, Hou Y, Welton NJ, Lin J, et al. Relative efficacy of different exercises for pain, function, performance and quality of life in knee and hip osteoarthritis: systematic review and network meta-analysis. Sports Med Auckl NZ. (2019) 49:743-61. doi: 10.1007/s40279-019-01082-0

65. Pazit L, Jeremy D, Nancy B, Michael B, George E, Hill KD. Safety and feasibility of high speed resistance training with and without balance exercises for knee osteoarthritis: a pilot randomised controlled trial. Phys Ther Sport Off J Assoc Chart Physiother Sports Med. (2018) 34:154-63. doi: 10.1016/j.ptsp.2018.10.001

66. Turner MN, Hernandez DO, Cade W, Emerson CP, Reynolds JM, Best TM. The role of resistance training dosing on pain and physical function in individuals with knee osteoarthritis: a systematic review. Sports Health. (2020) 12:200-6. doi: 10.1177/19417381198 87183

67. Ferraz RB, Gualano B, Rodrigues R, Kurimori CO, Fuller R, Lima $\mathrm{FR}$, et al. Benefits of resistance training with blood flow restriction in knee osteoarthritis. Med Sci Sports Exerc. (2018) 50:897-905. doi: 10.1249/MSS.0000000000001530

68. Hwang PS, Willoughby DS. Mechanisms behind blood flowrestricted training and its effect toward muscle growth. J Strength Cond Res. (2019) 33:S167-79. doi: 10.1519/JSC.00000000000 02384

69. Raeissadat SA, Ghazi Hosseini P, Bahrami MH, Salman Roghani R, Fathi M, Gharooee Ahangar A, et al. The comparison effects of intra-articular injection of Platelet Rich Plasma (PRP), Plasma Rich in Growth Factor (PRGF), Hyaluronic Acid (HA), and ozone in knee osteoarthritis; a one year randomized clinical trial. BMC Musculoskelet Disord. (2021) 22:134. doi: 10.1186/s12891-021-04017-x

70. Belk JW, Kraeutler MJ, Houck DA, Goodrich JA, Dragoo JL, McCarty EC. Platelet-rich plasma versus hyaluronic acid for knee osteoarthritis: a systematic review and meta-analysis of randomized controlled trials. Am J Sports Med. (2021) 49:249-60. doi: 10.1177/03635465209 09397

71. Fiuza-Luces C, Garatachea N, Berger NA, Lucia A. Exercise is the real polypill. Physiology. (2013) 28:330-58. doi: 10.1152/physiol.00019.2013

72. Falck RS, Best JR, Li LC, Chan PCY, Feehan LM, Liu-Ambrose T. Can we improve cognitive function among adults with osteoarthritis by increasing moderate-to-vigorous physical activity and reducing sedentary behaviour? Secondary analysis of the MONITOR-OA study. BMC Musculoskelet Disord. (2018) 19:447. doi: 10.1186/s12891-018-2369-z

73. Uzunkulaoglu A, Yildirim IB, Güneş Aytekin M, Ay S. Effect of flamingo exercises on balance in patients with balance impairment due to senile osteoarthritis. Arch Gerontol Geriatr. (2019) 81:48-52. doi: 10.1016/j.archger.2018.10.012 
74. Mihalko SL, Cox P, Beavers DP, Miller GD, Nicklas BJ, Lyles M, et al. Effect of intensive diet and exercise on self-efficacy in overweight and obese adults with knee osteoarthritis: the IDEA randomized clinical trial. Transl Behav Med. (2019) 9:227-35. doi: 10.1093/tbm/iby037

75. Van Ginckel A, Hall M, Dobson F, Calders P. Effects of long-term exercise therapy on knee joint structure in people with knee osteoarthritis: a systematic review and meta-analysis. Semin Arthritis Rheum. (2019) 48:9419. doi: 10.1016/j.semarthrit.2018.10.014

76. Kraus VB, Sprow K, Powell KE, Buchner D, Bloodgood B, Piercy K, et al. Effects of physical activity in knee and hip osteoarthritis: a systematic umbrella review. Med Sci Sports Exerc. (2019) 51:1324-39. doi: 10.1249/MSS.0000000000001944

77. Beckwée D, Vaes P, Raeymaeckers S, Shahabpour M, Scheerlinck T, Bautmans I. Exercise in knee osteoarthritis: do treatment outcomes relate to bone marrow lesions? A randomized trial. Disabil Rehabil. (2017) 39:1847-55. doi: 10.1080/09638288.2016.1212110

78. de Almeida AC, Pedroso MG, Aily JB, Gonçalves GH, Pastre CM, Mattiello SM. Influence of a periodized circuit training protocol on intermuscular adipose tissue of patients with knee osteoarthritis: protocol for a randomized controlled trial. BMC Musculoskelet Disord. (2018) 19:421. doi: 10.1186/s12891-018-2325-y

79. Bricca A, Wirth W, Juhl CB, Kemnitz J, Hunter DJ, Kwoh CK, et al. Moderate physical activity and prevention of cartilage loss in people with knee osteoarthritis: data from the osteoarthritis initiative. Arthritis Care Res. (2019) 71:218-26. doi: 10.1002/acr. 23791

80. Mazor M, Best TM, Cesaro A, Lespessailles E, Toumi H. Osteoarthritis biomarker responses and cartilage adaptation to exercise: a review of animal and human models. Scand J Med Sci Sports. (2019) 29:1072-82. doi: $10.1111 /$ sms. 13435

81. Goh S-L, Persson MSM, Stocks J, Hou Y, Lin J, Hall MC, et al. Efficacy and potential determinants of exercise therapy in knee and hip osteoarthritis: a systematic review and meta-analysis. Ann Phys Rehabil Med. (2019) 62:35665. doi: 10.1016/j.rehab.2019.04.006

82. Timmins KA, Leech RD, Batt ME, Edwards KL. Running and knee osteoarthritis: a systematic review and meta-analysis. Am J Sports Med. (2017) 45:1447-57. doi: 10.1177/03635465166 57531

83. Moseng T, Dagfinrud H, Smedslund G, Østerås N. The importance of dose in land-based supervised exercise for people with hip osteoarthritis. A systematic review and meta-analysis. Osteoarthritis Cartilage. (2017) 25:1563-76. doi: 10.1016/j.joca.2017.06.004

84. Elbadawy MA. Effectiveness of periosteal stimulation therapy and home exercise program in the rehabilitation of patients with advanced knee osteoarthritis. Clin J Pain. (2017) 33:254-63. doi: 10.1097/AJP.0000000000000404

85. Waller B, Munukka M, Rantalainen T, Lammentausta E, Nieminen MT, Kiviranta I, et al. Effects of high intensity resistance aquatic training on body composition and walking speed in women with mild knee osteoarthritis: a 4-month RCT with 12-month follow-up. Osteoarthritis Cartilage. (2017) 25:1238-46. doi: 10.1016/j.joca.2017.02.800

86. Suzuki $Y$, Iijima $H$, Tashiro $Y$, Kajiwara Y, Zeidan H, Shimoura K, et al. Home exercise therapy to improve muscle strength and joint flexibility effectively treats pre-radiographic knee OA in communitydwelling elderly: a randomized controlled trial. Clin Rheumatol. (2019) 38:133-41. doi: 10.1007/s10067-018-4263-3

87. Hanada K, Hara M, Hirakawa Y, Hoshi K, Ito K, Gamada K. Immediate effects of leg-press exercises with tibial internal rotation on individuals with medial knee osteoarthritis. Physiother Res Int J Res Clin Phys Ther. (2018) 23:e1725. doi: 10.1002/pri.1725

88. Bokaeian HR, Bakhtiary AH, Mirmohammadkhani M, Moghimi J. Quadriceps strengthening exercises may not change pain and function in knee osteoarthritis. J Bodyw Mov Ther. (2018) 22:528-33. doi: 10.1016/j.jbmt.2017.06.013

89. Zhao Z, Wang R, Guo Y, Chen L, Wang K, Zhou H, et al. Static low-angle squatting reduces the intra-articular inflammatory cytokines and improves the performance of patients with knee osteoarthritis. BioMed Res Int. (2019) 2019:9617923. doi: 10.1155/2019/9617923
90. Bartholdy C, Juhl C, Christensen R, Lund H, Zhang W, Henriksen M. The role of muscle strengthening in exercise therapy for knee osteoarthritis: a systematic review and meta-regression analysis of randomized trials. Semin Arthritis Rheum. (2017) 47:9-21. doi: 10.1016/j.semarthrit.2017.03.007

91. Marks R. Knee osteoarthritis and exercise adherence: a review. Curr Aging Sci. (2012) 5:72-83. doi: 10.2174/1874609811205010072

92. Driban JB, Price LL, Lynch J, Nevitt M, Lo GH, Eaton CB, et al. Defining and evaluating a novel outcome measure representing end-stage knee osteoarthritis: data from the Osteoarthritis Initiative. Clin Rheumatol. (2016) 35:2523-30. doi: 10.1007/s10067-016-3299-5

93. Power JD, Perruccio AV, Gandhi R, Veillette C, Davey JR, Syed K, et al. Neuropathic pain in end-stage hip and knee osteoarthritis: differential associations with patient-reported pain at rest and pain on activity. Osteoarthritis Cartilage. (2018) 26:363-9. doi: 10.1016/j.joca.2018.01.002

94. Kellgren JH, Lawrence JS. Radiological assessment of osteo-arthrosis. Ann Rheum Dis. (1957) 16:494-502. doi: 10.1136/ard.16.4.494

95. Radojčić MR, Thudium CS, Henriksen K, Tan K, Karlsten R, Dudley $A$, et al. Biomarker of extracellular matrix remodelling C1M and proinflammatory cytokine interleukin 6 are related to synovitis and pain in end-stage knee osteoarthritis patients. Pain. (2017) 158:1254-63. doi: 10.1097/j.pain.0000000000000908

96. Li W, Du C, Wang H, Zhang C. Increased serum ADAMTS-4 in knee osteoarthritis: a potential indicator for the diagnosis of osteoarthritis in early stages. Genet Mol Res. (2014) 13:9642-9. doi: 10.4238/2014.November.14.9

97. Ayanoglu T, Atalar H, Esen E, Ataoglu MB, Turanli S, Demircan K. The role of ADAMTS genes in the end stage of hip osteoarthritis. Acta Orthop Traumatol Turc. (2019) 53:140-4. doi: 10.1016/j.aott.2018. 12.007

98. Ethgen $\mathrm{O}$, Bruyère $\mathrm{O}$, Richy $\mathrm{F}$, Dardennes $\mathrm{C}$, Reginster J-Y. Health-related quality of life in total hip and total knee arthroplasty. A qualitative and systematic review of the literature. J Bone Joint Surg Am. (2004) 86:963-74. doi: 10.2106/00004623-200405000-00012

99. Singh JA, Lewallen DG. Predictors of activity limitation and dependence on walking aids after primary total hip arthroplasty. J Am Geriatr Soc. (2010) 58:2387-93. doi: 10.1111/j.1532-5415.2010.03182.x

100. Singh JA, O’Byrne M, Harmsen S, Lewallen D. Predictors of moderate-severe functional limitation after primary Total Knee Arthroplasty (TKA):4701 TKAs at 2-years and 2935 TKAs at 5-years. Osteoarthritis Cartilage. (2010) 18:515-21. doi: 10.1016/j.joca.2009.12.001

101. Pulik Ł, Jaśkiewicz K, Sarzyńska S, Małdyk P, Łegosz P. Modified frailty index as a predictor of the long-term functional result in patients undergoing primary total hip arthroplasty. Reumatologia. (2020) 58:213-20. doi: 10.5114/reum.2020.98433

102. Noehren B, Kosmac K, Walton RG, Murach KA, Lyles MF, Loeser RF, et al. Alterations in quadriceps muscle cellular and molecular properties in adults with moderate knee osteoarthritis. Osteoarthritis Cartilage. (2018) 26:1359-68. doi: 10.1016/j.joca.2018.05.011

103. Dávila Castrodad IM, Recai TM, Abraham MM, Etcheson JI, Mohamed NS, Edalatpour A, et al. Rehabilitation protocols following total knee arthroplasty: a review of study designs and outcome measures. Ann Transl Med. (2019) 7(Suppl. 7):S255. doi: 10.21037/atm.2019.08.15

104. Oatis CA, Johnson JK, DeWan T, Donahue K, Li W, Franklin PD. Characteristics of usual physical therapy post-total knee replacement and their associations with functional outcomes. Arthritis Care Res. (2019) 71:1171-7. doi: 10.1002/acr.23761

105. Hesseling B, Mathijssen NMC, van Steenbergen LN, Melles M, Vehmeijer SBW, Porsius JT. Fast starters, slow starters, and late dippers: trajectories of patient-reported outcomes after total hip arthroplasty: results from a Dutch nationwide database. J Bone Joint Surg Am. (2019) 101:2175-86. doi: 10.2106/JBJS.19.00234

106. Winther SB, Foss OA, Husby OS, Wik TS, Klaksvik J, Husby VS. A randomized controlled trial on maximal strength training in 60 patients undergoing total hip arthroplasty. Acta Orthop. (2018) 89:295-301. doi: 10.1080/17453674.2018.1441362

107. Liu H, Cong H, Chen L, Wu H, Yang X, Cao Y. Efficacy and safety of lower limb progressive resistance exercise for patients with total knee arthroplasty: a meta-analysis of randomized controlled trials. Arch Phys Med Rehabil. (2021) 102:488-501. doi: 10.1016/j.apmr.2020.05.021 
108. Doerfler D, Gurney B, Mermier C, Rauh M, Black L, Andrews R. High-velocity quadriceps exercises compared to slow-velocity quadriceps exercises following total knee arthroplasty: a randomized clinical study. J Geriatr Phys Ther. (2016) 39:147-58. doi: 10.1519/JPT.00000000000 00071

109. Hsu W-H, Hsu W-B, Shen W-J, Lin Z-R, Chang S-H, Hsu RW-W. Twentyfour-week hospital-based progressive resistance training on functional recovery in female patients post total knee arthroplasty. The Knee. (2019) 26:729-36. doi: 10.1016/j.knee.2019.02.008

110. Suh MJ, Kim BR, Kim SR, Han EY, Nam KW, Lee SY, et al. Bilateral quadriceps muscle strength and pain correlate with gait speed and gait endurance early after unilateral total knee arthroplasty: a cross-sectional study. Am J Phys Med Rehabil. (2019) 98:897-905. doi: 10.1097/PHM.0000000000001222

111. Kosek DJ, Kim J, Petrella JK, Cross JM, Bamman MM. Efficacy of 3 days/wk resistance training on myofiber hypertrophy and myogenic mechanisms in young vs. older adults. J Appl Physiol. (2006) 101:531-44. doi: 10.1152/japplphysiol.01474.2005

112. Stec MJ, Thalacker-Mercer A, Mayhew DL, Kelly NA, Tuggle SC, Merritt EK, et al. Randomized, four-arm, dose-response clinical trial to optimize resistance exercise training for older adults with age-related muscle atrophy. Exp Gerontol. (2017) 99:98-109. doi: 10.1016/j.exger.2017. 09.018

113. Bamman MM, Clarke MSF, Feeback DL, Talmadge RJ, Stevens BR, Lieberman SA, et al. Impact of resistance exercise during bed rest on skeletal muscle sarcopenia and myosin isoform distribution. J Appl Physiol. (1998) 84:157-63. doi: 10.1152/jappl.1998.84.1.157

114. Ferrando AA, Tipton KD, Bamman MM, Wolfe RR. Resistance exercise maintains skeletal muscle protein synthesis during bed rest. J Appl Physiol. (1997) 82:807-10. doi: 10.1152/jappl.1997.8 2.3.807

115. Sattler LN, Hing WA, Vertullo CJ. What is the evidence to support early supervised exercise therapy after primary total knee replacement? A systematic review and meta-analysis. BMC Musculoskelet Disord. (2019) 20:42. doi: 10.1186/s12891-019-2415-5

116. Chen X, Li X, Zhu Z, Wang H, Yu Z, Bai X. Effects of progressive resistance training for early postoperative fast-track total hip or knee arthroplasty: a systematic review and meta-analysis. Asian J Surg. (2021). doi: 10.1016/j.asjsur.2021.02.007. [Epub ahead of print].
Conflict of Interest: JS has received consultant fees from Crealta/Horizon, Medisys, Fidia, PK Med, Two labs Inc, Adept Field Solutions, Clinical Care options, Clearview healthcare partners, Putnam associates, Focus forward, Navigant consulting, Spherix, MedIQ, Jupiter Life Science, UBM LLC, Trio Health, Medscape, WebMD, and Practice Point communications; and the National Institutes of Health and the American College of Rheumatology. JS owns stock options in TPT Global Tech, Vaxart pharmaceuticals and Charlotte's Web Holdings, Inc. JS previously owned stock options in Amarin, Viking and Moderna pharmaceuticals. JS is on the speaker's bureau of Simply Speaking. JS is a member of the executive of Outcomes Measures in Rheumatology (OMERACT), an organization that develops outcome measures in rheumatology and receives arms-length funding from 8 companies. JS serves on the FDA Arthritis Advisory Committee. JS is the chair of the Veterans Affairs Rheumatology Field Advisory Committee. JS is the editor and the Director of the University of Alabama at Birmingham (UAB) Cochrane Musculoskeletal Group Satellite Center on Network Meta-analysis. JS previously served as a member of the following committees: member, the American College of Rheumatology's (ACR) Annual Meeting Planning Committee (AMPC) and Quality of Care Committees, the Chair of the ACR Meet-the-Professor, Workshop and Study Group Subcommittee and the co-chair of the ACR Criteria and Response Criteria subcommittee.

The remaining authors declare that the research was conducted in the absence of any commercial or financial relationships that could be construed as a potential conflict of interest.

Publisher's Note: All claims expressed in this article are solely those of the authors and do not necessarily represent those of their affiliated organizations, or those of the publisher, the editors and the reviewers. Any product that may be evaluated in this article, or claim that may be made by its manufacturer, is not guaranteed or endorsed by the publisher.

Copyright (c) 2021 Drummer, McAdam, Seay, Ferrando, Bridges, Singh and Bamman. This is an open-access article distributed under the terms of the Creative Commons Attribution License (CC BY). The use, distribution or reproduction in other forums is permitted, provided the original author(s) and the copyright owner(s) are credited and that the original publication in this journal is cited, in accordance with accepted academic practice. No use, distribution or reproduction is permitted which does not comply with these terms. 